\title{
Improvements in Perimeter Thoracic Mobility on Patients with COPD after Pulmonary Rehabilitation: A Case Series
}

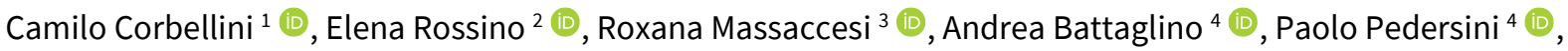 \\ Eleuterio A. Sánchez Romero ${ }^{5 *}$ (1), Jorge Hugo Villafañe ${ }^{4}$ (b)
}

\author{
${ }^{1}$ Department of Physiotherapy, LUNEX International University of Health, Exercise and Sports, LUXEMBOURG \\ ${ }^{2}$ AOU San Luigi Gonzaga, Orbassano, ITALY \\ ${ }^{3}$ Casa di Cura Villa Serena, Piossasco (TO), ITALY \\ ${ }^{4}$ IRCCS Fondazione Don Carlo Gnocchi, Milan, ITALY \\ ${ }^{5}$ Department of Physiotherapy, Faculty of Sport Sciences, Universidad Europea de Madrid, Villaviciosa de Odón, Madrid, SPAIN \\ `Corresponding Author: eleuterio.sanchez@universidadeuropea.es
}

Citation: Corbellini C, Rossino E, Massaccesi R, Battaglino A, Pedersini P, Sanchez-Romero EA, Villafañe JH. Improvements in Perimeter Thoracic Mobility on Patients with COPD after Pulmonary Rehabilitation: A Case Series. Electron J Gen Med. 2022;19(3):em361. https://doi.org/10.29333/ejgm/11671

\begin{tabular}{|c|c|}
\hline ARTICLE INFO & ABSTRACT \\
\hline Received: 7 Dec. 2021 & if the perimeter thoracic mobility (PTM) improvements could be identified by $\mathrm{me}$ \\
\hline
\end{tabular}
functional assessments.

Design: A case series.

Methods: Twenty patients underwent a PR and accessed the arterial blood gas analyses, FVC, FEV1, FEV/FEV1, 6minute walk test (6MWT), and the PTM measurement assessed at the angle of the Louis level and the xiphoid process level.

Results: PR improved PTM on the angle of Louis $(\mathrm{p}=0.03)$ but not on the xiphoid process. These improvements are negatively correlated with improvements in $\mathrm{PaCO}_{2}$.

Conclusions: In COPD patients, a successful PR is accompanied by a reduction of the upper chest wall resting perimeter and by an improvement of the perimeter thoracic mobility.

Clinical relevance: The centimeter tape is a useful device able to identify PTM improvements in COPD patients.

Keywords: chronic obstructive pulmonary disease, exercise, pulmonary rehabilitation

\section{INTRODUCTION}

Chronic obstructive pulmonary disease (COPD) is characterized by persistent respiratory symptoms, which is due to airway abnormalities, destruction of the lung parenchyma decreasing the lung elastic recoil [1]. The modification of the respiratory mechanics may cause progressive limitation of exercise capacity, resulting in a worsening of the clinical and functional status and quality of life [2].

It has been speculated that motion abnormalities, progressive stiffening and alteration in regional volumes of the chest wall [3] may play a role in the onset of breathlessness during exercise in COPD patients. These changes raise the question of whether pulmonary rehabilitation can reduce abnormal chest wall movement in COPD patients, thereby restoring exercise capacity and reducing dyspnea [4].

However, the assessment of perimeter thoracic mobility (PTM) in clinical practice requires reliable measures that do not consume time and economic resources. The measurement of the PTM by a centimeter tape measure is a technique already described (also called cirtometry) both in healthy subjects [5] and in patients suffering from respiratory diseases [6]. The PTM consists of a set of standardized chest perimeter measurements during different respiratory capacities to evaluate the chest wall expansion during the respiration, and. Its reliability was confirmed by $[7,8]$.

Cirtometry application in the field of pulmonary rehabilitation (PR) remains controversial [9], nevertheless more sophisticated instruments [10] to assess PTM in a COPD patient are not often available. So, it is important, for a respiratory physiotherapist, to use an easy technique to guide the clinical practice, permitting the possibility to assess the already known improvements in respiratory mechanics [11].

We designed this study to evaluate whether it is possible to identify the PTM improvements by measuring its perimeter during PR, searching for correlations between the PTM improvements with standard clinical and functional assessments. 


\section{METHODS}

\section{Study Design}

This study is a prospective case series. Informed consent was obtained from all participants. The procedures were conducted according to the Declaration of Helsinki, respecting the Italian law regarding the privacy and utilization of the patients' data for research purposes. The protocol was approved by the Ethical Committee Comitato Etico Interaziendale A.O.U. San Luigi Gonzaga Di Orbassano, Protocol Number 005212.

\section{Participants}

We assessed 20 consecutive COPD patients (6 women) admitted at Casa di Cura Villa Serena, Piossasco (TO), Italy. All patients were older than 18 years and had been diagnosed with COPD, with severity determined according to the global initiative for chronic obstructive lung disease (GOLD) criteria. The exclusion criteria were: patients with tracheostomy, inability to perform Spirometry, hemodynamic instability, unstable angina or myocardial infarction, congestive heart failure, and any neurological or orthopedic condition that could inhibit patients from participating in the PR.

\section{Protocol and Outcomes}

All patients followed the same evaluation protocol on the first and last PR day. Vital signs, height, weight, and body mass index (BMI) were assessed. The patients were submitted to an arterial blood gas analysis (ABGA), 6-minute walking test (6MWT), and spirometry.

The thoracic perimeter measurements were performed by a trained physiotherapist that executed the evaluation protocol exclusively before and after the PR. The technique was performed according to previously described protocols [12] with patients in a sitting position with the arms hanging tightly to the thorax. An average tape measure was placed around the chest at the axillary level, just over the angle of Louis (ALL) and over the xiphoid process level (XPL). The measurements were taken when the patient inhaled: at the functional residual capacity (FRC), after a quiet expiration (rest position); at total lung capacity (TLC): (slow deep inspiration) and residual volume (RV) (slow deep expiration) [8]. After those measurements, the perimeter thoracic mobility (PTM) was determined by calculating the difference between the measurements made at TLC and the perimeter measured at RV $(\Delta \mathrm{TLC}-\mathrm{RV})$.

Following this procedure, it was performed according to the ATS/ERS statements [13,14], the 6MWT and the spirometry, with a digital spirometer (Vmax, Viasys Healthcare Inc, USA). The PR followed the ATS/ERS guidelines [15]. The PR physical training consisted of a protocol that was comprised of upper and lower limb strength training. Cycloergometer continuous training (work rate target to find $60 \%$ to $70 \%$ of the theoric maximal heart rate for each patient) for a total of 70 minutes a day (40 minutes for the aerobic endurance training, and the rest lower limb training according to the patients tollererance, reaching $60 \%$ of $1 \mathrm{RM}$ as workload), five days a week during $4 \pm 0.5$ weeks. During the hospitalization, the patients received medication according to the medical clinic evaluation.
Table 1. Baseline demographics

\begin{tabular}{|c|c|c|}
\hline Characteristics & Mean & SD \\
\hline Age & 76 & \pm 5 \\
\hline Female gender $(\mathrm{n}(\%))$ & \multicolumn{2}{|l|}{$6(30 \%)$} \\
\hline Smoking (Yes) & \multicolumn{2}{|l|}{$9(45 \%)$} \\
\hline Time of recover (Days) & 28 & \pm 3 \\
\hline Height (cm) & 161.7 & \pm 10.5 \\
\hline Weight (kg) & 69.9 & \pm 13.4 \\
\hline BMI & 26.9 & \pm 5.8 \\
\hline $\mathrm{pH}$ & 7.43 & \pm 0.04 \\
\hline $\mathrm{PaO}_{2}(\mathrm{mmHg})$ & 62.0 & \pm 9.7 \\
\hline $\mathrm{PaCO}_{2}(\mathrm{mmHg})$ & 46.1 & \pm 8.4 \\
\hline $\mathrm{HCO}_{3}(\mathrm{mmHg})$ & 30.1 & \pm 4.8 \\
\hline $\mathrm{PaO}_{2} / \mathrm{FiO}_{2}$ & 262.6 & \pm 58.7 \\
\hline $\mathrm{SpO}_{2}(\%)$ & 92.1 & \pm 3.7 \\
\hline FVC (\%) & 80.1 & \pm 30.7 \\
\hline $\mathrm{FEV}_{1}(\%)$ & 56.6 & \pm 28.1 \\
\hline $\mathrm{FEV}_{1} / \mathrm{FVC}$ & 54.4 & \pm 16.0 \\
\hline \multicolumn{3}{|c|}{$\begin{array}{l}\text { Note. BMI: Body mass index; } \mathrm{SpO}_{2}: \text { Partial oxygen saturation; } \mathrm{pH} \\
\text { Hydrogenionic potential; } \mathrm{PaO}_{2}: \mathrm{Partial} \text { arterial oxygen pressure; } \mathrm{PaCO}_{2} \\
\text { Carbon dioxide partial pressure; } \mathrm{HCO}_{3}: \mathrm{Bicarbonate} \text { mmHg: Millimeter of } \\
\text { mercury; } \mathrm{cm} \text { : Centimeters; kg: Kilograms; } \mathrm{PaO}_{2} / \mathrm{FiO}_{2}: \mathrm{Partial} \text { arterial oxygen } \\
\text { pressure/Inspiratory oxygen fraction ratio; } \mathrm{FVC} \text { Forced vital capacity; } \mathrm{FEV}_{1} \\
\text { Forced expiratory volume on } 1 \text { second }\end{array}$} \\
\hline
\end{tabular}

\section{Data Analysis}

Data were analyzed using SPSS package version 25.0 (SPSS Inc, Chicago, IL, USA). We used the Kolmogorov-Smirnov test, the One-way analysis of variance (ANOVA) with repeated measurements, and Bonferroni was used as a posthoc test. Cohen's d coefficient is used to determine sample effect size. The Spearman's rank correlation coefficient (Rs) was used to evaluate the relationship between PTM with the other parameters, and $\mathrm{p}<0.05$ was considered statistically significant.

\section{RESULTS}

The baseline characteristics are listed in Table 1.

The mobility at ALL ( $\triangle T L C-R V)$ improved significantly $(F=14.095, p=0.03)$, with improvements between pre vs. posttreatment $(p=0.001)$. A small within-group effect size $(d<0.2)$ was found between pre-treatment and post-treatment. The distance walked improved $(F=9.179, p=0.008)$ as did the distance walked/ predicted distance ratio. A small withingroup effect size $(\mathrm{d}<0.2)$ was found between pre-treatment and post-treatment (Table 2).

The $\mathrm{HCO} 3, \mathrm{PaO} 2 / \mathrm{FiO} 2$, and $\mathrm{SpO} 2$ improved for time interaction $(F=7.893 ; p=0.01, F=20.207 ; p=0.001$, and $F=10.415$; $\mathrm{p}=0.005$, respectively). The post hoc analysis revealed significant differences pre/post PR (all, $p<0.01$ ).

The PTM improvements at the ALL presented a moderate negative correlation to the $\mathrm{pCO} 2$ and $\mathrm{HCO} 3$ (Rs= -0.618 and 0.552 , respectively, and all $\mathrm{p}<0.02$ ) and positive correlation to the FVC and FEV1 (Rs= 0.511 and 0.512, respectively, both $\mathrm{p}=0.02$ ).

\section{DISCUSSION}

This study aimed to measure thoracic movement changes after pulmonary rehabilitation for chronic obstructive 
Table 2. Mean (SD) for outcome at all study visits and mean (SD) difference within group

\begin{tabular}{|c|c|c|c|c|c|}
\hline \multirow{2}{*}{ Outcome } & & \multicolumn{2}{|c|}{ Group } & \multirow{2}{*}{$\begin{array}{l}\text { Effect size } \\
\text { Cohen's d }\end{array}$} & \multirow{2}{*}{$\begin{array}{c}\text { Difference within group } \\
\text { Post minus pre }(n=20)\end{array}$} \\
\hline & & Pre(n=20) & Post(n=20) & & \\
\hline \multirow{8}{*}{ Cyrtometry } & Angle Louis FRC & $99.6(9.6)$ & $96.9(8.8)$ & 0.3 & $-2.7(-7.2 ; 1.8)$ \\
\hline & Angle Louis TLC & 101.3(9.6) & $99.1(9.0)$ & 0.2 & $-2.2(-6.6 ; 2.2)$ \\
\hline & Angle Louis RV & $98.7(9.4)$ & $96.1(9.3)$ & 0.3 & $-2.6(-7.0 ; 1.7)$ \\
\hline & Angle Louis $\Delta$ TLC-RV & $2.6(1.1)$ & $3.0(1.1)$ & -0.4 & $0.4 \#(-0.04 ; 0.8)$ \\
\hline & Xiphoid process FRC & $97.7(11.7)$ & $96.8(11.8)$ & 0.04 & $-0.9(-2.5 ; 0.7)$ \\
\hline & Xiphoid process TLC & 99.1(11.4) & $98.4(11.5)$ & 0.06 & $-0.7(-2.2 ; 0.7)$ \\
\hline & Xiphoid process RV & $97.0(11.7)$ & $96.0(11.6)$ & 0.9 & $-1.0(-2.6 ; 0.6)$ \\
\hline & Xiphoid process $\Delta$ TLC-RV & $2.2(1.3)$ & $2.5(1.1)$ & -0.2 & $0.3(-0.4 ; 0.9)$ \\
\hline \multirow{2}{*}{ 6MWT } & Distance $(\mathrm{m})$ & $233.1(109.5)$ & $327.6(90.8)$ & -0.9 & $94.5 \#(28.7 ; 160.4)$ \\
\hline & $\% /$ Predicted distance & $73.6(8.4)$ & $94.7(6.5)$ & -2.8 & $21.1^{\star}(9.7 ; 32.5)$ \\
\hline \multirow{6}{*}{ ABGA } & $\mathrm{pH}$ & $7.43(0.04)$ & $7.42(0.03)$ & 0.3 & $0.01(-0.03 ; 0.02)$ \\
\hline & $\mathrm{PaO}_{2}(\mathrm{mmHg})$ & $62.0(9.9)$ & $70.2(9.7)$ & -0.8 & $8.2(3.1 ; 13.3)$ \\
\hline & $\mathrm{PaCO}_{2}(\mathrm{mmHg})$ & $46.1(8.6)$ & $43.5(8.0)$ & 0.3 & $-2.6(-5.3 ; 0.09)$ \\
\hline & $\mathrm{HCO}_{3}(\mathrm{mmHg})$ & $30.1(4.9)$ & $28.0(3.4)$ & 0.5 & $-2.1^{\star}(-3.6 ;-0.5)$ \\
\hline & $\mathrm{PaO}_{2} / \mathrm{FiO}_{2}$ & $260.7(59.7)$ & $309.3(56.0)$ & -0.8 & $48.5^{\star}(16.9 ; 80.1)$ \\
\hline & $\mathrm{SpO}_{2}(\%)$ & $91.9(3.7)$ & $94.8(2.4)$ & -0.9 & $2.9^{\star}(1.6 ; 4.3)$ \\
\hline
\end{tabular}

\# Significantly different within-group, $\mathrm{P}<0.05$ (95\% confidence interval); * Significantly different within-group, $\mathrm{P}<0.001$ (95\% confidence interval)

FRC: Functional residual capacity; TLC: Total lung capacity; RV: Residual volume; $\triangle T L C-R V$ : Difference between the total lung capacity and the residual volume; 6MWT: 6 minute walking test; $\mathrm{ABGA}$ : Arterial blood gases analyzes; $\mathrm{pH}$ : Hydrogenionic potential; $\mathrm{PaO}_{2}$ : $\mathrm{Partial}_{\text {arterial oxygen pressure; } \mathrm{PaCO}}$ :

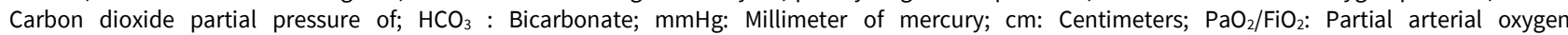
pressure/Inspiratory oxygen fraction ratio; $\mathrm{SpO}_{2}$ : Partial oxygen saturation; FVC: Forced vital capacity; FEV ${ }_{1}$ : Forced expiratory volume on 1 second

pulmonary disease. From this perspective, we showed that a simple centimeter tape could identify Perimeter thoracic mobility improvements in COPD patients. The chest wall seems to increase its mobility (at ALL), followed by improvements in the $A B G A$ and functional performance. In addition, these improvements are followed by a hypercapnia, peripheric oxygen saturation, oxemia improvements. In moderate to severe COPD subjects, we found a mean $0.4 \mathrm{~cm}(0.0-0.8 \mathrm{~cm})$ improvement in the PTM at the level of angle of Louis and 0.3 $\mathrm{cm}(-0.4$ to $0.9 \mathrm{~cm})$ at the xiphoid process level. However, the statistical significance of the PTM at xiphoid process level was not achieved in the present study.

Dynamic hyperinflation (DH) increases the thoracicabdominal volume and is one of the main factors causing dyspnea and exercise limitation in COPD subjects DH [4]. Furthermore, hyperinflated patients are more likely to develop abnormalities in PTM, playing a role in breathlessness [16]. PR can reduce the degree of dynamic hyperinflation [17-20] and end-expiratory ribcage volume [4,14,21,22], partially restoring the upper and lower thoracic mobility restoring, dyspnea and exercise tolerance [4]. However, to determine variations of rib cage volume, the optoelectronic plethysmography is necessary.

Regarding PTM, it was demonstrated that a minimum of 0.6 $\mathrm{cm}$ of thoracic excursion should be considered to use this kind of assessment technique. But they demonstrated their results in healthy volunteers without demonstrating the mean circumferences values [8]. In [12], the authors, in another way, had correlated lung function and the measurement of the thoracic perimeter (they called cirtometry) in healthy subjects, and they found a positive weak but statistically relevant, the correlation between the thoracic circumference and FEV1 and FVC. Besides, in this study, the mean thoracic circumference excursion at the angle of Louis was $6.3 \pm 2 \mathrm{~cm}$, almost the double of our values in COPD subjects, and these differences may be explained by the known pulmonary hyperinflation and thoracic stiffness that COPD patients present. Both studies suggested the use of this technique in settings with different kinds of subjects as COPD patients.
We cannot state that the PTM improvements observed in our study $(0.4 \mathrm{~cm})$ are clinically relevant. We have not any other study to compare our results, because as far as we know, this is the only research that used the thoracic circumference measurement as a PR outcome. We also identified a moderate negative correlation between the PTM and the PaCO2. The association between the hypercapnia, chest wall volume enhancement, and respiratory muscle activation is well documented. But the study presented a model with healthy individuals where the upper rib cage end-expiratory volume increased during increasing of end-tidal PCO2 [23]. This model did not show any association between end-tidal PCO2 levels and thoracic perimeter.

Our study has limitations related to its design. The control group was not planned, but this is in accordance with the explorative nature of the work. Moreover, regardless of the sample size effect determination, a study with a more significant, the sample may determine consistent results in the mean PTM improvements. In female patients, PTM at the xiphoid level may be more difficult due to morphological reasons.

In conclusion, this study provided an effective alternative method to evaluate thoracic mobility in COPD subjects because it is time saver, inexpensive, and easy to adopt in everyday clinical practice. Nevertheless, future randomized controlled trials should investigate the validity and reliability of PTM compared with more sophisticated motion capture systems and larger sample sizes.

We tried to determine a confident and straightforward way to identify thoracic movements, abnormalities, and improvements via the chest wall movements in the context of PR. The centimeter tape could be useful to add information when the standard lung functioning tests were not available. Further research with this technique might help in the interpretation of PTM, especially in the presence of mild-tosevere COPD. The sample size and lack of a control group were the main limitations.

Author contributions: All authors have sufficiently contributed to the study, and agreed with the results and conclusions. 
Funding: No funding source is reported for this study.

Declaration of interest: No conflict of interest is declared by authors.

\section{REFERENCES}

1. Singh D, Agusti A, Anzueto A, et al. Global strategy for the diagnosis, management, and prevention of chronic obstructive lung disease: The GOLD science committee report 2019. Eur Respir J. 2019;53(5):1900164. https://doi.org/10.1183/13993003.00164-2019 PMid: 30846476

2. Oga T, Nishimura K, Tsukino M, Sato S, Hajiro T. Analysis of the factors related to mortality in chronic obstructive pulmonary disease: Role of exercise capacity and health status. Am J Respir Crit Care Med. 2003;167(4):544-9. https://doi.org/10.1164/rccm.200206-5830C PMid: 12446268

3. Aliverti A, Stevenson N, Dellacà RL, Lo Mauro A, Pedotti A, Calverley PM. Regional chest wall volumes during exercise in chronic obstructive pulmonary disease. Thorax. 2004;59(3):210-6. https://doi.org/10.1136/thorax.2003. 011494 PMid:14985554 PMCid:PMC1746979

4. Gagliardi E, Innocenti Bruni G, Presi I, Gigliotti F, Scano G. Thoraco-abdominal motion/displacement does not affect dyspnea following exercise training in COPD patients. Respir Physiol Neurobiol. 2014;190:124-30. https://doi.org/ 10.1016/j.resp.2013.10.005 PMid:24140573

5. Fronczek M, Mysłek K, Sajek A, Padula G, Kopacz K. Effect of diaphragm postisometric relaxation in older adults. Top Geriatr Rehabil. 2019;35(2):104-7. https://doi.org/10.1097/ TGR.0000000000000207

6. de Souza GHM, Ferraresi C, Moreno MA, et al. Acute effects of photobiomodulation therapy applied to respiratory muscles of chronic obstructive pulmonary disease patients: A double-blind, randomized, placebo-controlled crossover trial. Lasers Med Sci. 2020;35(5):1055-63. https://doi.org/10.1007/s10103-019-02885-3 PMid: 31654154

7. Bockenhauer SE, Chen H, Julliard KN, Weedon J. Measuring thoracic excursion: Reliability of the cloth tape measure technique. J Am Osteopath Assoc. 2007;107(5):191-6. PMid:17596587

8. da Silva Caldeira V, Starling CC, Britto RR, Martins JA, Sampaio RF, Parreira VF. Reliability and accuracy of cirtometry in healthy adults. J Bras Pneumol. 2007;33(5):519-26. https://doi.org/10.1590/s180637132007 000500006 PMid:18026649

9. Nici L, Donner C, Wouters E, et al. American Thoracic Society/European Respiratory Society statement on pulmonary rehabilitation. Am J Respir Crit Care Med. 2006;173(12):1390-413. https://doi.org/10.1164/rccm.2005 08-1211ST PMid:16760357

10. Massaroni C, Carraro E, Vianello A, et al. Optoelectronic plethysmography in clinical practice and research: A review. Respiration. 2017;93(5):339-54. https://doi.org/ 10.1159/000462916 PMid:28329750

11. Corbellini C, Boussuges A, Villafañe JH, Zocchi L. Diaphragmatic mobility loss in subjects with moderate to very severe COPD may improve after in-patient pulmonary rehabilitation. Respir Care. 2018;63(10):1271-80. https://doi.org/10.4187/respcare.06101 PMid:30065081
12. de Cordoba Lanza F, de Camargo AA, Archija LR, Selman JP, Malaguti C, Dal Corso S. Chest wall mobility is related to respiratory muscle strength and lung volumes in healthy subjects. Respir Care. 2013;58(12):2107-12. https://doi.org/ 10.4187/respcare.02415 PMid:23674814

13. Enright PL, Sherrill DL. Reference equations for the sixminute walk in healthy adults. Am J Respir Crit Care Med. 1998;158(5):1384-7. https://doi.org/10.1164/ajrccm.158.5. 9710086 PMid:9817683

14. Miller MR, Hankinson J, Brusasco V, et al. Standardisation of spirometry. Eur Respir J. 2005;26(2):319-38. https://doi.org/10.1183/09031936.05.00034805 PMid: 16055882

15. Spruit MA, Singh SJ, Garvey C, et al. An official American Thoracic Society/European Respiratory Society statement: key concepts and advances in pulmonary rehabilitation. Am J Respir Crit Care Med. 2013;188(8):e13-64. https://doi. org/10.1164/rccm.201309-1634ST PMid:24127811

16. Jubran A, Tobin MJ. The effect of hyperinflation on rib cageabdominal motion. Am Rev Respir Dis. 1992;146(6):137882. https://doi.org/10.1164/ajrccm/146.6.1378 PMid: 1456551

17. Georgiadou O, Vogiatzis I, Stratakos G, et al. Effects of rehabilitation on chest wall volume regulation during exercise in COPD patients. Eur Respir J. 2007;29(2):284-91. https://doi.org/10.1183/09031936.00121006 PMid: 17107987

18. Puente-Maestu L, Abad YM, Pedraza F, Sánchez G, Stringer WW. A controlled trial of the effects of leg training on breathing pattern and dynamic hyperinflation in severe COPD. Lung. 2006;184(3):159-67. https://doi.org/10.1007/ s00408-005-2576-x PMid:16902841

19. Scichilone N, La Sala A, Bellia M, et al. The airway response to deep inspirations decreases with COPD severity and is associated with airway distensibility assessed by computed tomography. J Appl Physiol (1985). 2008;105(3):832-8. https://doi.org/10.1152/japplphysiol. 01307.2007 PMid:18617628 PMCid:PMC2536818

20. Wilkens H, Weingard B, Lo Mauro A, Schena E, Pedotti A, Sybrecht GW, Aliverti Aet al. Breathing pattern and chest wall volumes during exercise in patients with cystic fibrosis, pulmonary fibrosis and COPD before and after lung transplantation. Thorax. 2010;65(9):808-14. https://doi.org /10.1136/thx.2009.131409 PMid:20805177

21. Aliverti A, Quaranta M, Chakrabarti B, Albuquerque AL, Calverley PM. Paradoxical movement of the lower ribcage at rest and during exercise in COPD patients. Eur Respir J. 2009;33(1):49-60. https://doi.org/10.1183/09031936. 00141607 PMid:18799505

22. Vogiatzis I, Stratakos G, Athanasopoulos D, et al. Chest wall volume regulation during exercise in COPD patients with GOLD stages II to IV. Eur Respir J. 2008;32(1):42-52. https://doi.org/10.1183/09031936.00155207 PMid: 18321930

23. Yan S, Sliwinski P, Macklem PT. Association of chest wall motion and tidal volume responses during $\mathrm{CO} 2$ rebreathing. J Appl Physiol (1985). 1996;81(4):1528-34. https://doi.org/10.1152/jappl.1996.81.4.1528 PMid: 8904564 